\title{
BUDAYA KEMISKINAN NELAYAN KECIL DAN BURUH NELAYAN
}

\author{
Riki Yulianda', Arfriani Maifizar ${ }^{2}$, Sopar $^{3}$ \\ Universitas Teuku Umar \\ rikiyulianda@utu.ac.id, arfrianimaifizar@utu.ac.id, sopar@utu.ac.id
}

\begin{abstract}
The culture of poverty is a problem of poverty caused by factors habits of everyday life in sociaty. Culture of poverty in fishers society, especially small fishers and labor fishers, becouse habits of everyday life continues on regeneration sociaty. So that the fishers sociaty is trapped in this situation. Poverty is the powerless individual in realizing the welfare of life, many factor influence poverty in society, that is natural, structural, human resources, and culture of povelty. This research in only focuses on one factor of poverty, that is culture factors. The research discusses the culture of poverty on small fishers and labor fishers in West Aceh. The purpose is to determine the potrait of poverty that is caused by culture factors. The methodology used is a qualitatif methodology by using a contructivist paradigm and informant determination with technique of selecting small fishers and labor fishers who are active at sea. Data analysis was done through narrative analysis based on the chronology experienced by individuals or communities from small fishers and labor fishers. The result of this study explain the portrait and reproduction of poverty which is coused by culture factors, the discussion is related to financial management, in the fishers house and and tradition from generation to generation. Patterns of behavior and human resources in fishing communities and fishing workers on the coast in West Aceh.
\end{abstract}

Keywords: Reproduction of poverty, small fishers, labor fishers, and culture of poverty

\section{PENDAhULUAN}

Budaya kemiskinan merupakan suatu kemiskinan dalam kehidupan masyarakat yang disebabkan oleh kebiasaan masyarakat secara turn temurun. Kemiskinan yang disebabkan oleh faktor budaya merupakan salah satu penyebab terjadinya kemiskinan dari berbagai kalangan masyarakat, baik dikalangan buruh, petani bahkan masyarakat nelayan. Kemiskinan disebabkan oleh beberapa faktor, diantaranya faktor kesengajaan, kultural dan faktor rendahnya keterampilan hidup masyarakat. Proses terbentuknya kelas yaitu struktur sosial yang terbentuk sebagai akibat dari struktur sosial yang lain, misalnya stratifikasi sosial, termasuk kelas sosial, terbentuk karena adanya struktur sosial berupa sistem kepemilikan (property right) (Kinseng, 2017). 
Faktor kesengajaan (struktural) belum menjelaskan secara keseluruhan terhadap masalah kemiskinan, tetapi masih ada faktor lain yang menjadi jebakan kemiskinan (poverty trap) yaitu faktor budaya dan rendahnya ketrampilan hidup masyarakat. Budaya kemiskinan yaitu suatu kebudayaan yang terjadi pada kehidupan orang miskin seperti pola perilaku, nilai, norma, kondisi sosial dan psikologis (Lewis, 2016). Kemiskinan menjadi persoalan besar pada nelayan kecil dan buruh nelayan yang masih terjadi secara turun temurun, kasus nelayan di Aceh masih tergolong miskin dan menarik untuk dikaji. Fokus penelitian ini tentang budaya kemiskinan nelayan kecil dan buruh nelayan di Aceh Barat, dengan tujuan penelitian yaitu untuk menganalisis potret budaya kemiskinan nelayan kecil dan buruh nelayan di Kabupaten Aceh Barat. Berdasarkan uraian pada pendahuluan, kemiskinan nelayan kecil dan buruh nelayan suatu hal yang sulit untuk diatasi, karena terjadinya faktor ketimpangan antara pendapatan nelayan yang tidak sesuai dengan kebutuhan nelayan untuk memenuhi kebutuhan hidup sehari-hari. Berdasarkan latar belakang di atas dapat dirumuskan masalah penelitiannya adalah tentang potret dan proses reproduksi kemiskinan pada nelayan kecil dan buruh nelayan yang disebabkan oleh faktor budaya.

\section{TINJAUAN PUSTAKA}

Teori yang digunakan untuk menganalisis permasalahan dalam penelitian ini yaitu teori budaya kemiskinan (cultural of poverty) yang dikemukakan oleh oscar Lewis. Teori itu menguraikan tentang kehidupan masyarakat miskin yang menjelaskan tentang pola perilaku, tatanan nilai, dan tradisi suatu masyarakat yang sudah turun temurun, seperti pendidikan renadah, pola hidup yang meniru kelas menengah ke-atas, padah dia berada dikelas bawah, ketergantungan yang tinggi dan sikap rendah diri, tinggal dipermukiman kurang layak, dan mempersingkat waktu bermain (Lewis, 2016).

Berdasarkan penjelasan Lewis, perilaku orang miskin di Indonesia, khususnya masyarakat nelayan dan buruh nelayan memiliki pola perilaku yang serupa, memiliki tatanan nilai yang sulit dirubah, fanatik terhadap tradisi yang sudah turun temurun, misalnya seperti pola hidup konsumtif pada saat musim panen ikan tiba, dan memiliki kekurangan, serta menjual aset rumah tangga dalam menutupi ansuran pinjaman ketika musim paceklik tiba. Di samping itu kebiasaan masyarakat nelayan yang hanya mengandalkan kehidupan dari hasil tangkapan dari laut mereka yang pada umunya tidak memiliki keterampilan hidup lainnya seperti bertukang, berdagang atau sebagi buruh bangunan hanya dapat menghabiskan waktu untuk aktivitas yang kurang bermanfaat. Faktor penyebab kemiskinan pada masyarakat nelayan dilihat dari sudut pandang budaya yaitu pendidikan rendah, kebiasaan nelayan, tidak tersedianya pekerjaan alternatif, dan teknologi yang digunakan (Hamdani, 2013). Pendapat yang sama kemiskinan kultural dapat dilihat dari rendahnya pendidikan, mengandalkan tenaga fisik, ketiadaan lembaga, dan gaya hidup yang konsumtif (Tahawila, 2014). 
104

Community: Volume 7, Nomor 1, April 2021

p-ISSN: 2477-5746 e-ISSN: 2502-0544

Budaya kemiskinan merupakan kemiskinan yang terjadi akibat pengaruh nilainilai yang berlaku pada lingkungan tempat tinggal masyarakat baik secara individu, keluarga dan masyarakat secara turun-temurun dan menjadi suatu kebiasaan hidup atau budaya. Kemiskinan ini terjadi akibat jebakan kemiskinan yang terjadi pada generasi awal tidak bisa terjadinya mobilitas sosial vertikal naik antar individu pada regenerasinya (Palikah, 2016). Budaya kemiskinan disebabkan oleh terjadinya Persistent poverty yaitu kemiskinan yang telah kronis atau turun temurun. Daerah yang penduduk tergolong miskin pada umumnya merupakan daerah-daerah yang kritis sumberdaya alam, atau daerah terisolasi, sehingga tidak memiliki akses jalan dan transportasi dengan daerah lainnya (Nurwati, 2008). Kondisi nelayan kecil dan buruh nelayan jika dikaitkan dengan kemiskinan kultural merupakan suatu persistent poverty yang sudah terjadi secara turun temurun karena tidak mampu mewujudkan mobilitas sosial vertikal intrapribadi dan mobilitas sosial vertikal antar pribadi. Kemiskinan ini terus terjadi pada kehidupan regenerasi. Menanggulangi kemiskinan yang terdapat pada penduduk miskin bukanlah tugas yang ringan, karena berhubungan erat dengan berbagai masalah kehidupan seperti keadaan daerah, kegiatan penduduk, tingkat pendidikan dan kesehatan.

Kasus yang berkaitan dengan budaya kemiskinan yaitu menerangkan tentang kemiskinan strategis yaitu kemiskinan yang terbentuk akibat pilihan hidup, ketika seorang individu dengan modal sosial dan budaya mengadopsi kehidupan berpenghasilan rendah untuk membentuk identitas sosial lainnya. Contoh kasus, Anne seorang wanita setengah baya yang menjalankan rumah Katolik Worker yang merupakan tempat penampungan untuk tunawisma, mengungkapkan suatu perspektif yang sangat mengejutkan yaitu pilihan untuk tetap miskin terlepas dari kelas menengah dan pendidikan. Untuk Anne kemiskinan merupakan suatu konsekuensi tidak lansung dari kehidupannya yang dipilih karena kedudukannya sebagai aktivis, dengan kata lain lembaga di mana Anna beroperasi menetapkan kondisi berpenghasilan rendah dan ia harus hidup dengan penghasilan rendah tersebut (Demetry dan Thurk, 2013). setiap orang memiliki nilai-nilai budaya, norma-norma dan model mendarah daging itu adalah budaya yang mengajarkan kita tentang skema kognitif terhadap pandangan kita terhadap dunia. Setiap orang dari kita memiliki identitas budaya tersendiri sehingga terbawa dalam diri kita dan mampu membedakan antara satu kelompok dengan kelompok lain (Bugra, 2014). Akar kemiskinan nelayan adalah ketergantungan yang tinggi terhadap kegiatan penangkapan. Kurangnya penyadaran nelayan terhadap kondisi ekosistem perairan yang mudah berubah-ubah setiap saat sehingga bisa berpengaruh terhadap pendapatan nelayan. Akar kemiskinan nelayan juga disebabkan oleh rendahnya keterampilan nelayan untuk melakukan diversifikasi kegiatan penangkapan dan keterikatan yang kuat terhadap pengoperasian satu jenis alat tangkap dan untuk menangkap jenis ikan tertentu maka ketika tidak sedang musim ikan jenis tersebut, nelayan hanya memiliki peluang yang sedikit (Kusnadi, 2003). Pasca tsunami, sebagian 
kecil masyarakat pesisir yang desanya tidak layak untuk dijadikan pemukiman penduduk maka direlokasikan ketempat yang baru, dari tempat yang baru tersebut masyarakat sulit beradaptasi karena kondisi alam yang tidak potensial dalam mengembangkan ekonomi rumah tangga. Fenomena itu mayoritas para suami bekerja keluar, ada yang menjadi nelayan, petani dan juga ada yang menjadi buruh, sedangkan kaum ibu hanya menjadi buruh rumah tangga yang tidak produktif (Maifizar, 2016).

Hilangnya kemandirian dalam mengentaskan kemiskinan masyarakat nelayan kecil dan buruh nelayan, karena ketergantungan berlebihan kepada pihak donor yang memberikan bantuan modal kepada mereka semenjak pasca tsunami (Yulianda dkk, 2013). Mengkaji permasalahan budaya kemiskinan pada masyarakat nelayan, baik nelayan kecil maupun buruh nelayan merupakan mengkaji penyebab kemiskinan yang disebabkan oleh pola perilaku, nilai, norma, kondisi sosial dan psikologis masyarakat nelayan di wilayah penelitian. Teori budaya kemiskinan juga mendapat kritikan dari para ilmuan, seperti Valentine, Ridge and Wright dan lain-lainnya, karena mereka tidak setuju terhadap kemiskinan yang disebabkan oleh faktor budaya, namun ada faktor lain yang menyebabkan kemiskinan yaitu faktor struktural.

\section{METODE PENELITIAN}

Penelitian ini dilakukan di kawasan pemukiman nelayan pesisir Kabupaten Aceh Barat karena wilayah ini masih ditemukan kemiskinan nelayan kecil dan buruh nelayan. Pendekatan penelitian ini yaitu menggunakan metodologi kualitatif, dengan paradigma kontruktivistik, sumber data yang disajikan yaitu data primer dikumpulkan dari masyarakat yang bekerja sebagai nelayan kecil dan buruh nelayan dan data sekunder diperoleh dari internet dan dinas terkait, yang berkaitan dengan penelitian ini berupa profil kabupaten, dan populasi nelayan yang ada di Kabupaten Aceh Barat. Teknik pengumpulan data dalam penelitian ini dilakukan dengan cara observasi tidak terlibat langsung dan wawancara mendalam (in depth interview), wawancara bebas dan spontan (the informal interview) dengan beberapa informan, nelayan kecil dan buruh nelayan. Hasil penelitian dianalisis menggunakan analisis naratif kualitatif. Analisis naratif (narrative analysis) yaitu analisis data kualitatif yang menyajikan rangkaian peristiwa yang terpaut secara kronologis dengan pelaku individu atau pelaku sosial (Neuman, 2015). Analisis dalam penelitian ini dilakukan berdasarkan kronologis yang terjadi pada individu atau masyarakat, baik dari nelayan kecil maupun buruh nelayan.

\section{HASIL DAN PEMBAHASAN}

Budaya kemiskinan merupakan suatu nilai, pola perilaku dan norma yang sudah terinternalisasi dalam kehidupan orang miskin dan telah menjadi kebiasaan secara turun temurun. Lewis menjelaskan budaya kemiskinan dapat muncul sebagai akibat nilai dan budaya yang dianut oleh orang miskin itu sendiri. Budaya kemiskinan di kalangan 
106

Community: Volume 7, Nomor 1, April 2021

p-ISSN: 2477-5746 e-ISSN: 2502-0544

keluarga nelayan kecil dan buruh nelayan terdiri dari manajemen keuangan dan adatistiadat, serta pola perilaku (Palikah, 2016).

\subsection{Manajemen Keuangan, dan Adat-Istiadat}

Kegagalan dalam mengelola keuangan pada rumah tangga nelayan kecil dan buruh nelayan disebabkan oleh faktor belanja yang sulit terkontrol rumah tangga yang sulit terkontrol, karena lebih banyak kebutuhan dari pada pendapatan dan tabungan. Pengeluaran merupakan bagian dari modal finansial, besarnya pengeluaran dari pendapatan mengakibatkan ketidak seimbangan ekonomi pada rumah tangga nelayan kecil dan buruh nelayan, karena, semua pendapatan habis untuk memenuhi kebutuhan konsumsi, dan kebutuhan sosial.

Fakta empiris kehidupan tentang kehidupan nelayan kecil dan buruh nelayan yaitu, berbagai macam kebutuhan yang harus dipenuhi oleh nelayan kecil dan buruh nelayan setiap hari, setiap bulan dan setiap tahun. Kebutuhan tersebut mulai dari kebutuhan sandang, pangan atau kebutuhan individu rumah tangga nelayan, kebutuhan sosial, adat-istiadat dan keagamaan. Banyaknya kebutuhan tersebut menjadi suatu kesulitan bagi nelayan kecil dan buruh nelayan dalam mengelola keuangan. Kegagalan mengelola keuangan oleh nelayan kecil dan buruh nelayan karena masalah yang multidimensional, seperti masalah ekonomi, sosial budaya, psikologi dan lain-lainnya. Siklus setiap tahun memperingati momentum yang sangat sakral seperti hari besar Islam diantaranya meugang, puasa Ramadhan, Idul Fitri, Idul Adha, Maulid Nabi Muhammad SAW, Isra' Mikraj dan kenduri lainnya yang berdasarkan adat-istiadat seperti kenduri jeurat (kenduri kuburan), kenduri blang (kenduri sawah), kenduri laot (kenduri laut) serta menghadiri undangan hajatan setiap bulan pasti ada antara satu sampai tiga tempat hajatan. Hajatan sering dilaksanakan pada rumah tangga kelas menengah ke atas, sedangkan pada rumah tangga orang miskin sangat jarang kecuali hanya melaksanakan kenduri Maulid. Pengeluaran sulit terkontrol ketika tiba bulan-bulan tersebut karena pendapatan tidak stabil dan tabungan tidak tersedia.

\subsection{Pola Perilaku}

Pola perilaku sehari-hari nelayan kecil dan buruh nelayan yaitu pada saat musim panen tiba kebiasaan dari nelayan kecil dan buruh nelayan memiliki pendapatan di atas indikator kemiskinan, pola konsumsi meningkat pada kebutuhan tersier yaitu pengeluaran yang tidak terkendali seperti kebiasaan saling mentraktir teman-teman di warung kopi. Selain itu, juga rentan membeli sesuatu yang tidak penting seperti televisi, kulkas dan bahkan membeli motor. Proses pembelian tersebut tidak semuanya dibeli secara tunai, namun juga bersifat hutang (kredit). Ketika musim paceklik dan peralihan musim tiba, penghasilan tangkapan nelayan menurun di bawah indikator yang telah ditetapkan oleh Badan Pusat Statistik (BPS), sehingga mereka berada dalam situasi yang sulit bahkan yang membeli motor dengan sistem kredit rentan ditarik oleh petugas yang 
bertugas menagih hutang tersebut, keadaan semakin rumit karena tidak mampu membayar tarif listrik bulanan, akhirnya daftar hutang pada tetangga, koperasi dan lembaga keuangan bukan bank dengan jaminan Buku Pemiliki Kendaraan bermotor (BPKB), pinjaman tersebut bukan digunakan untuk membuka usaha, namun untuk melunasi hutang motor, iuran listrik dan hutang lainnya yang belum terbayar. Siklus perputaran terhadap kondisi tersebut terus terjadi dalam jangka panjang sehingga sulit untuk keluar, karena pola konsumsi yang tidak sesuai dengan kebutuhan atau sebagai gaya hidup. Musim paceklik ialah masa sulit secara finansial bagi nelayan, banyak yang terpaksa menjual barang-barang seperti Televisi (TV), radio, atau sesuatu yang berharga milik mereka untuk bertahan hidup. Banyak juga yang meminjamkan uang pada tengkulak sehingga menjalin hubungan patron-klien yang sangat eksploitatif (Kinseng, 2017).

\subsection{Sumber Daya Manusia}

Sumber daya manusia dibutuhkan bagi setiap manusia, karena menentukan nasip seseorang dalam mensikapi peluang yang tersedia. Sumber daya manusia yaitu modal manusia yang meliputi kesehatan, nutrisi, pendidikan, Skill (keahlian) yang dibutuhkan setiap orang untuk menjadi produktif secara ekonomi. Pendidikan formal suatu kebutuhan yang harus dipenuhi pada setiap individu, karena pendidikan formal mampu mencerdaskan, merubah pola pikir, pola perilaku seseorang yang penuh dinamika. Jika di tinjau dari sudut pandang budaya kemiskinan, hal ini terjadi karena anak-anak dari keluarga nelayan kecil dan buruh nelayan sebagian besar bekerja sebagai buruh cuci kapal nelayan setelah nelayan pulang dari laut, sehingga mereka meperoleh upah dari hasil cuci perahu nelayan dan malas untuk sekolah. Sebagian anak-anak dari nelayan kecil dan buruh nelayan ada yang sekolah, namun pulang sekolah juga bekerja mencuci kapal, kemudian mendapat upah dari pekerjaan tersebut, akhirnya putus sekolah, karena sudah merasakan nikmat uang dari upah bekerja sendiri dan bisa digunakan untuk menguatkan ekonomi keluarga atau untuk memenuhi kebutuhan sendiri.

Reproduksi kemiskinan berdasarkan tingkat pendidikan yang dilihat dari sudut pandang budaya kemiskinan yaitu anak-anak dari nelayan kecil dan buruh nelayan terpengaruhi dengan nilai-nilai yang berkembang dilingkungannya, seperti kebanyakan anak-anak nelayan dan buruh nelayan tidak sekolah karena sudah sering memperoleh uang dari jerih payah mereka bekerja mencuci kapal nelayan ketika pulang dari melaut. Jika yang sudah sekolah mereka tidak fokus pada pendidikannya dan selalu bolos untuk menuju sungai menunggu perahu nelayan pulang. Sebagian dari anak-anak dari nelayan kecil dan buruh nelayan merasa malas dengan membiayai sendiri sekolahnynya akhirnya keluar dari sekolah fokus pada pekerjaan saja, hanya sebahagian kecil yang tidak sepakat dengan nilai yang berlangsung dalam keluarga, namun tetap untuk melanjutkan pendidikan ke perguruan tinggi dengan modal inspirasi diri yang tinggi. Kesadaran masyarakat nelayan, baik nelayan kecil maupun buruh nelayan terhadap 
108

Community: Volume 7, Nomor 1, April 2021

p-ISSN: 2477-5746 e-ISSN: 2502-0544

pendidikan anak-anaknya masih rendah, hal ini dipengaruhi oleh tingkat pendidikan orang tua yang tidak memahami arti penting pendidikan formal bagi anak-anaknya. Hal ini ditandai dengan membiarkan anaknya untuk bekerja di laut untuk ikut mencari uang dan mengabaikan pendidikan anak (Siregar, 2016). Kesadaran kelas dalam pendidikan formal anak dari nelayan kecil dan buruh nelayan disebabkan oleh budaya masyarakat yang sudah berlomba-lomba melanjutkan ke pendidikan formal ke jenjang yang lebih tinggi. Wright menjelaskan unsur kesadaran kelas ini mencakup kepercayaan, ide, observasi, informasi, teori dan kesukaan (preferences) (Kinseng, 2014). Aspek pendidikan hanya mampu bertahan pada orang kelas menengah ke atas, karena mereka mampu menginvestasikan untuk menempuh pendidikan tinggi, agar mampu mengarah pada usaha agen yang menghasilkan keahlian tertentu, sedangkan kelas menengah ke bawah hanya mampu mempertahankan modal budaya yang ada. Masalah sumber daya manusia selain mempelajari pendidikan formal, juga mengkaji masalah keahlian yang terbatas (skill) (Wangka, 2010).

\section{PENUTUP}

Potret kemiskinan nelayan kecil dan buruh nelayan terjadi pada musim paceklik (masa sulit) dan musim pancaroba, pada musim panen banyak dari mereka yang sejahtera. Perbedaan tingkat pendidikan antara kedua orang tua nelayan kecil dengan kedua orang tua buruh nelayan tidak terlalu mencolok. Peningkatan jenjang pendidikan pada nelayan kecil dan buruh nelayan sudah mulai terjadi walaupun masih dalam jumlah kecil. Reproduksi kemiskinan terjadi disebabkan oleh faktor budaya kemiskinan yaitu manajemen keuangan dan adat-istiadat, pola perilaku dan sumber daya manusia. Semua aspek yang terjadi karena dipengaruhi oleh sistem nilai yang berlaku secara turun temurun, sehingga menjadi suatu kebiasaan dan mental menerabas dari keluarga miskin pada rumah tangga nelayan kecil dan buruh nelayan.

\section{DAFTAR PUSTAKA}

Bugra, D. 2014. Putting Curture Back Into Psyichiatry. World Journal of Medical Educationt Research Volum 8(1). www.wjmer.co.uk.

Demetry, D, Thurk, JFG. 2013. Strategic Poverty: How Social and Cultural Capital Shapes Low-Income life. Journal of Consumer Cutural 0 (0) 1-24. Northwestern University. academia.edu.

Hamdani, H W K. 2013. Faktor Penyebab Kemiskinan Nelayan Tradisional.[. Jurnal Http://Repository.Unej.Ac.Id.

Kinseng, RA. 2014. Konflik Nelayan. Jakarta: Pustaka Obor Indonesia.

Kinseng, RA. 2017. Struktugensi: Sebuah Teori Tindakan. Sodality. Jurnal Sosiologi Pedesaan. hal 127-137. 
Kusnadi. 2003. Akar Kemiskinan Nelayan.Yogyakarta: LKis.

Lewis, O .2016. Kisah Lima Keluarga: Telaah-Telaah Kasus Orang Meksiko dalam Kebudayaan Kemiskinan. Ed 2. Jakarta: Yayasan Obor Indonesia.

Maifizar, A. 2016. Karakteristik Dan Fenomena Kemiskinan Keluarga Miskin Pedesaan Di Aceh. Community, 2(3).

Neuman WR. 2015. Metodelogi Penelitian Sosial: Pendekatan Kualitatif dan Kuantitatif.Jakarta: PT Indeks.

Nurwati, N. 2008. Kemiskinan Model Pengukuran, Permasalahan dan Alternatif Kebijakan. Jurnal Kependudukan Padjadjaran, Vol 10(1).jurnal.unpad.ac.id.

Palikah N. 2016. Konsep Kemiskinan Kultural. Ilmu Dakwa, Vol 15(30).http://jurnal.uinantasari.ac.id.

Siregar. 2016. Kesadaran Masyarakat Nelayan Terhadap Pendidikan Anak. ASE, vol 4(1) hlm 1-10. http://ojs.umn.ac.id.

Suharto, B. 2018. Analisis Faktor-Faktor yang Mempengaruhi Kemiskinan di Kalimantan Timur Pada Era Desentraslisasi Fiskal (Kajian Pada Aspek Sumber Daya Alam dan Sumber Daya Manusia. Surabaya: Fakultas Ekonomi Bisnis Universitas Brawijaya.

Tahawila A. 2014. Studi Akar Kemiskinan Nelayan Di Kelurahan Baiya Kecamatan Tawaeli Kota Palu. E Jurnal Katalogis, 2(7).

Wangka WM. 2010. Mengentaskan Kemiskinan. ASE, 6(2) hlm 17-21.repo.unsrat.ac.id.

Yulianda, R dkk. 2013. Fenomena Kemiskinan Masyarakat Relokasi Pasca Tsunami di Kecamatan Arongan Lambalek Kabupaten Aceh Barat. Proseding Aceh Development International Conference Acdemi of Islamic Studies; 2013, hal 238-244. Kuala Lumpur: University of Malaya. 